\title{
Conexões, apropriações e exclusões no discurso do desenvolvimento territorial no Brasil
}

\section{Connections, appropriations and exclusions in the discourse of territorial development in Brazil}

José Renato Sant'Anna Porto - Doutorando do Programa de Pós-Graduação de Ciências Sociais em Desenvolvimento, Agricultura e Sociedade da Universidade Federal Rural do Rio de Janeiro (CPDA/UFRRJ). E-mail: jreporto3@gmail.com

\section{Resumo}

Este artigo objetiva propor uma organização dos discursos que influenciaram as políticas públicas de desenvolvimento territorial, e busca identificar alguns dos principais debates que desencadearam conotações específicas e significados particulares às ideias de "território" e "desenvolvimento territorial" no Brasil. A opção escolhida foi sistematizar a bibliografia buscando identificar abordagens e conceitos que influenciaram essas políticas públicas, bem como perceber a maneira como outros temas vão sendo progressivamente acoplados ao longo do tempo. O intuito principal é iniciar o mapeamento das formas como o discurso do "território" nas políticas públicas de desenvolvimento rural vai ganhando corpo e se tornando uma ideia que ordena e articula atores sociais, ao estabeler determinados princípios de interação, comunicação e ação. Busca-se, ainda, discutir o "outro lado" deste mesmo processo, em que, a meu ver, a política territorial seria parte de um processo histórico de mais longa data, que tem como um de seus efeitos a reificação da categoria "agricultura familiar" e a obstacularização (ou substituição) do debate sobre questões agrárias e fundiárias no escopo das ações e políticas governamentais para o rural.

\section{Palavras-chave}

Desenvolvimento territorial. Agricultura familiar. Discursos.

\begin{abstract}
Abstract: This article aims to propose an organization of discourses and narratives that have influenced public policy of territorial development, and seeks to identify some of the key debates that put specific connotations and meanings to the ideas of "territory" and "territorial development" in Brazil. In this sense, the chosen option was to systematize and organize the vast literature on this topic in order to identify the main approaches and concepts that influenced those policies and see how other issues are progressively engaged over time. The main goal here is to begin mapping the ways in which the discourse of "territory" in rural development policies is slowly becoming an idea ordering and articulates social actors, confirming certain principles of interaction, communication and action. At the same time, I try to also observe and discuss the "other side" in which, in my view, territorial policy would be part of a historical process of longer standing, which has as one of its effects strengthening the concept of "family farm" and the lock (or replacement) of the debate on agrarian and land issues in the scope of government actions and policies for rural.
\end{abstract}

\section{Keywords}

Territorial development. Family farm. Discourses. 


\section{DESENVOLVIMENTO TERRITORIAL: ORIGENS, TRAJETÓRIAS E SUA INFLUÊNCIA NAS POLÍTICAS PÚBLICAS DE DESENVOL- VIMENTO RURAL}

A tarefa de remontar o caminho pelo qual a ideia de território foi sendo gradativamente incorporada às políticas públicas não é, em si, uma grande novidade no meio acadêmico interessado na discussão sobre políticas públicas e desenvolvimento rural. Alguns autores já se dedicaram a essa empreitada (FAVARETO, 2010; LEITE; DELGADO, 2011; MONTENEGRO, 2006), e o resultado desses esforços é parte importante do conteúdo a ser considerado neste artigo. De todo modo, o mapeamento que pretendo realizar na pesquisa em andamento ${ }^{1}$ busca considerar um contexto de relações mais ampliado, de forma a situar o processo de incorporação da abordagem territorial no campo de relações políticas que recebem, apropriam e remodelam a proposta de desenvolvimento territorial, conferindo particularidades e distinções próprias à experiência brasileira. Neste sentido, buscarei identificar não apenas os debates que gradativamente compuseram e alicerçaram as políticas de desenvolvimento territorial rural no Brasil, mas também atentarei para aqueles que ficaram de fora do escopo dessa nova forma de conceber as políticas públicas e ordenar os atores no meio rural. Ou seja, por ora, o foco está menos na descrição do conteúdo e da institucionalidade proposta por essas políticas e mais no processo de produção político-epistemológica da política pública (SHORE; WRIGHT; PERÒ, 2011), a partir da observação dos discursos e das formas de conhecimento que vão paulatinamente influenciando e conferindo uma forma específica à política pública. Ao observar o processo de incorporação de desses conteúdos, o que pretendo aqui é tecer um panorama geral a esse respeito, buscando fazer algumas inferências preliminares acerca das possíveis consequências político-institucionais e cognitivas que são derivadas dessa dinâmica de construção. Em síntese, buscarei mapear os efeitos desencadeados, tanto aqueles mais evidentes, que implicam em transformações na condução das políticas públicas, quanto os efeitos indiretos, que implicam em impactos mais sutis sobre a ação dos atores que se engajam nessas políticas públicas.

Em sentido amplo, o enfoque territorial para as políticas públicas de desenvolvimento rural remete a um leque bastante diverso de temáticas. Ideias como "gestão social", "territórios rurais", "competitividade territorial",

Este artigo é parte da sistematização dos discursos e narrativas que sustentam a política de desenvolvimento territorial no Brasil, cuja análise e problematização são objeto de minha tese em construção. 
“articulação de políticas públicas", "participação social”, "fortalecimento dos atores sociais", "articulação urbano-rural" e "desenvolvimento sustentável" (MDA, 2005) são algumas das noções que compõem esse novo vocábulo das políticas de desenvolvimento rural, e que passa a constituir um a priori para toda e qualquer ação dos atores que se envolvem no ambiente sociopolítico criado a partir dessas políticas públicas. Ao mesmo tempo, a incorporação de tais conceitos implica uma renovação também no âmbito das institucionalidades das políticas de desenvolvimento rural, em que novas estruturas, instrumentos e espaços de interação, como, por exemplo, os "colegiados territoriais", os "Planos Territoriais de Desenvolvimento Rural Sustentável" e as "matrizes de projetos" (MDA, 2005) aparecem como dispositivos ordenadores das relações entre os atores envolvidos. Tanto as ideias e os conceitos quanto os instrumentos de gestão, intervenção e "governança" não emergem do nada; são todos frutos de um processo específico o qual tentarei resgatar ao longo deste artigo.

Seguindo a orientação de Schneider e Tartaruga (2006), não devemos confundir o sentido prático e aplicado da noção de desenvolvimento territorial rural, por exemplo, na implementação e no desenho de políticas públicas, com o uso do território como instrumento de análise dos fenômenos sociais em um dado local. Ou seja, os autores propõem uma distinção entre o que seria o “território-categoria analítica" e o "território-abordagem de intervenção". Esta separação organizativa é um ponto de partida interessante para adentrarmos nos debates sobre desenvolvimento territorial rural, no que tange à sua mobilização no âmbito das políticas públicas, centrando a atenção na ideia de território como uma abordagem de intervenção recente, que passa a ser incorporada no escopo das políticas públicas para o desenvolvimento rural, e que, como veremos, também implica em transformações e influências, na prática e no discurso, a uma série de atores e grupos sociais.

Obviamente essa dissociação não é algo estanque, e por mais que consigamos isolar provisoriamente as distintas utilizações do termo "território", isto é, o uso normativo e o uso analítico, sabemos que a influência entre eles é mútua. De todo modo, não é qualquer perspectiva analítica que incida sobre a noção de território que influenciará as políticas de desenvolvimento territorial rural. A título de exemplificação, podemos observar a conceituação de "território" estabelecida no âmbito das políticas públicas da SDT/MDA.

[...] um espaço físico, geograficamente definido, geralmente contínuo, compreendendo a cidade e o campo, caracterizado por critérios multidimensionais - tais como o ambiente, a economia, a sociedade, a cultura, a política e as instituições - e uma população com grupos sociais 
relativamente distintos, que se relaciona interna e externamente por meio de processos específicos, onde se pode distinguir um ou mais elementos que indicam identidade e coesão social, cultural e territorial (MDA, 2005).

A definição apresentada acima expõe um caráter normativo do território, o qual deve ser estruturado com base nos preceitos e elementos predefinidos. Ou seja, trata-se de um território idealizado, em que, a partir de intervenções de políticas públicas, será possível alcançar determinado status desejado. Destacamse, dentre as considerações postas, o elemento do consenso entre os atores e o objetivo da construção de um projeto "identitário-econômico", partindo justamente da "concertação social" que seria promovida pelas políticas públicas. Existe, portanto, um “dever ser", que passa por uma conciliação dos objetivos e interesses dos grupos e indivíduos que estão no território. Pleiteia-se um território sem conflitos, ou melhor, com conflitos, desde que gerenciáveis e solucionáveis na instância da "concertação social". Avançarei neste debate mais adiante. Por ora, gostaria de refletir um pouco mais sobre o processo de consolidação da ideia de desenvolvimento territorial rural e as influências que incidiram nessa construção.

Um ponto central é a negação do acúmulo conquistado por algumas disciplinas (notadamente pela Geografia, que tem o território como uma de suas principais categorias de interpretação da realidade) no processo de formulação do referencial que define os parâmetros da chamada "abordagem territorial". Mas, se por um lado, a Geografia, em especial a vertente da geografia política, que toma o território como um espaço de relações de poder, não parece ter sido considerada no processo de emergência da perspectiva territorial no âmbito das políticas públicas de desenvolvimento rural, por outro, diversas áreas de conhecimento tiveram contribuições significativas e grande influência nessa construção.

Já foi reiterado em várias contribuições que o trabalho de Arnaldo Bagnasco (1977) sobre a industrialização difusa na Itália teria sido um dos embriões do que mais tarde veio a se chamar de abordagem do desenvolvimento territorial. Através da observação do entrelaçamento de questões sociológicas e econômicas, Bagnasco verificou a existência de processos sociais particulares na região central da Itália, que permitiam o desenvolvimento de circuitos locais de produção capazes de conferir dinamismo econômico e gerar consequências e efeitos positivos (externalidades positivas) sobre o contexto local. A tese defendida é que as possibilidades de dinamismo local aumentam significativamente em territórios possuidores de características propícias à geração de complementaridades socioeconômicas entre ambientes rurais e urbanos, em 
caráter difuso e descentralizado. Ou seja, nas constatações de Bagnasco (1977) e de outros trabalhos que seguiram este mesmo enfoque, a dimensão territorial da produção, bem como a organização social pré-existente, são questões centrais, que, no caso, passam a influenciar a agenda dos debates voltados à promoção do desenvolvimento de regiões até então "não desenvolvidas".

Ao mesmo tempo, outro conjunto de questões incidiu no processo de elaboração inicial da ideia de "desenvolvimento territorial”" (mesmo que no início não fosse precisamente esta a denominação), oriundo das discussões teóricas que passavam a refletir sobre a evolução e as transformações contemporâneas do mundo rural, particularmente no contexto europeu. Como bem demonstra Favareto (2010), toda discussão sobre as novas ruralidades ou ruralidades avançadas na Europa (particularmente nos países de "capitalismo avançado"), caracterizadas pela proliferação de sinergias urbano-rurais e pelo consequente crescimento de atividades não agrícolas nos contextos rurais, também apontavam para a necessidade de modificações na esfera da intervenção sobre o rural. Nesse sentido, para além do caráter cada vez mais pluriativo do meio rural europeu, que passava a demandar outras formas de apoio que não apenas o tradicional crédito agrícola, emerge também a noção de que seria necessária uma escala de planejamento e intervenção que superasse a dicotomia urbano/rural. É certamente nesse contexto em que a ideia de território, como unidade espacial de intervenção e como perspectiva integradora, passa a ganhar relevância, não só no âmbito acadêmico, mas também, e principalmente, no escopo das diretrizes gerais para políticas públicas de intervenção sobre o rural.

Seguindo este enfoque, em meados da década de 1980 e início dos anos 1990, a abordagem territorial passa a constituir-se como um novo paradigma que incide na formatação de diversas políticas de promoção do desenvolvimento, principalmente no escopo dos organismos internacionais, tais como o Banco Mundial, a Organização das Nações Unidas para a Agricultura e Alimentação (FAO), a Organização para a Cooperação e o Desenvolvimento Econômico (OCDE) e, no contexto latino americano, a Comissão Econômica para América Latina (CEPAL), o Instituto Interamericano de Cooperação Agrícola (IICA) e o Centro Latinoamericano para o Desarrollo Rural (RIMISP). Tais organizações tiveram um papel muito importante na difusão da abordagem territorial, seja na articulação com governos nacionais, seja em parcerias com organizações não governamentais para a ação em perspectiva subnacional ou mesmo no financiamento de instituições acadêmicas e grupos de pesquisa. Essa abrangência que a abordagem territorial assume no âmbito dessas grandes instituições formuladoras de políticas, juntamente com a intensificação da 
produção acadêmica sob a mesma égide, garante a formação de um discurso fortificado, que cumpriu um papel de orientação de políticas públicas em prol do desenvolvimento rural, com abordagem territorial.

Ainda no contexto europeu, um marco importante na adoção da abordagem do desenvolvimento rural em escala territorial é a experiência do Programa LEADER (Ligações Entre Ações de Desenvolvimento das Economias Rurais), que estabeleceu uma ruptura com relação aos modelos de intervenção setoriais nos contextos rurais, e de certa forma inspirou a concepção de políticas territoriais mundo a fora, inclusive no Brasil, como veremos mais adiante. $O$ programa LEADER, iniciado em 1991, foi a primeira inciativa que incorporou, de fato, a abordagem territorial no sentido de uma estratégia intersetorial de desenvolvimento rural (como superação do enfoque essencialmente agrícola). Foi, também, como sinaliza Favareto (2010), pioneiro na execução de políticas organizadas a partir de uma prerrogativa bottom-up, que insere o elemento da participação e a consideração de um amplo rol de atores sociais como pré-condição para o desenho e implementação das diretrizes de desenvolvimento rural. É, então, a partir da construção desta proposta de arranjo institucional que esses dois elementos específicos, "intersetorialidade" e "participação social", passam a ser entrelaçados, e posteriormente acabam implicando em diversas evoluções em termos de estrutura organizacional para as políticas de desenvolvimento rural.

$\mathrm{Na}$ sua revisão sobre a emergência do programa LEADER, Favareto menciona outro elemento importante, referente à dimensão histórica na qual este programa surge, atinente ao contexto político de expansão do receituário neoliberal sobre as políticas de intervenção estatal. Mesmo sem investir muito na problematização e nos possíveis desdobramentos deste fato, o autor lembra que:

[...] é preciso reconhecer que isso acontece num contexto histórico marcado por uma crise e um realinhamento dos instrumentos tradicionais de promoção do desenvolvimento. A descentralização das políticas [...] associada à redução e ao redirecionamento da intervenção estatal, contribuíram para que, particularmente em meados das décadas de 1980 e 1990, se instituísse um padrão em que, em lugar dos investimentos diretos e de corte setorial, caberá ao Estado proporcionar condições e um ambiente a partir do qual os agentes privados pudessem, eles mesmos, fazer a alocação, supostamente mais eficiente, dos recursos humanos e materiais. Aqueles processos sociais e econômicos de corte eminentemente territorial e esse novo padrão são, em síntese, as principais razões de emergência e consolidação dessa nova abordagem institucional (FAVARETO, 2010, p. 25). 
Desse modo, parece ser significativamente importante para as análises sobre as institucionalidades e os arranjos propostos pela abordagem territorial remontar a essa origem histórica contextualizada. Temas como participação, governança e concertação social, na maioria das vezes ganham conotações meramente operacionais, que os afastam do contexto político em que emergem (ou reaparecem). Não pretendo aqui simplesmente questionar ou diminuir os importantes efeitos desencadeados pelos arranjos participativos desta e de outras políticas (com ou sem o adjetivo "territorial"), embora a crítica recente venha assinalando o potencial restrito dessas institucionalidades (DELGADO; GRISA, 2013) e o desgaste da agenda da participação, nos termos em que a mesma foi até então conduzida, ou seja, em que as experiências foram restringidas ao que Dagnino (2002) denominou de "confluência perversa". O intuito é apenas ressaltar este elemento do contexto histórico, entendendo se tratar de uma questão importante para ser problematizarda.

Outro elemento que aparece como um componente importante na formulação da abordagem do desenvolvimento territorial é a questão da regulação dos recursos naturais. Através de uma forte construção discursiva acerca da importância da proteção dos recursos naturais, a ideia de sustentabilidade passa a ser parte constitutiva na construção e definição dos parâmetros normativos da abordagem do desenvolvimento territorial. Essa associação entre a sustentabilidade e a emergência da questão territorial é verificada também por Offen (2003), ao discutir a relação entre o que ele denomina como territorial turn, relativo à criação de territórios étnicos na América Latina, e os interesses do Banco Mundial em mapear e demarcar áreas naturais com expressiva biodiversidade. Ou seja, nessa dimensão da sustentabilidade, é importante também levar em consideração o contexto político de construção do Estado-regulação e o seu papel na formatação das propostas de gestão dos recursos naturais.

\section{AGRICULTURA FAMILIAR, QUESTÃO AGRÁRIA E DESENVOL- VIMENTO TERRITORIAL: MUDANÇAS E REORIENTAÇÕES NO DEBATE SOBRE O RURAL BRASILEIRO}

Pensando especificamente na experiência brasileira, no que diz respeito à ideia de desenvolvimento territorial, hoje bastante reconhecida, principalmente no contexto latino-americano, pela experiência particular das políticas públicas articuladas pela SDT/MDA, é também importante que façamos algumas considerações acerca da trajetória e do contexto em que a abordagem territorial passa a ser validada como uma orientação para a produção de políticas de 
desenvolvimento rural. Ainda mantendo como referência a detalhada revisão feita por Favareto (2010), bem como o olhar crítico sobre o mesmo processo empreendido por Montenegro (2006), podemos elencar um movimento específico no âmbito acadêmico, que teria preparado o terreno para a consolidação da abordagem territorial no escopo das políticas públicas para o rural.

Segundo Favareto (2010), a produção acadêmica brasileira sobre o rural teve, neste período (início da década de 1990), uma influência significativa dos debates e problemáticas em voga no contexto europeu, mesmo que isso não tenha ocorrido de maneira homogênea. Ou seja, aquela agenda de pesquisa relacionada às novas expressões contemporâneas do rural e às complementaridades entre rural e urbano, especialmente a partir do caso francês, passaram a guiar também as interpretações sobre o rural brasileiro.

Um exemplo interessante que Montenegro (2006) apresenta sobre a paulatina modificação do enfoque no estudo do rural, diz respeito ao foco editorial da revista Estudos Avançados, editada pela Universidade de São Paulo, no que concerne especificamente a esta temática. O autor aponta que se em 1997 a revista lançou um dossiê cujo foco esteve na discussão da questão agrária como principal chave interpretativa para problematizar e pensar as questões atinentes ao rural, apenas quatro anos mais tarde, em 2001, a mesma revista lança outro dossiê com o propósito de problematizar a recente noção de desenvolvimento rural. Embora o editorial afirme o caráter diversificado das reflexões apresentadas nos artigos, o tom preponderante é o da aceitação da ideia de desenvolvimento rural como um novo paradigma para a conceituação do rural, o que aponta para a constituição de uma agenda de pesquisa que já vinha alcançando impactos e influências significativas para além dos muros da academia, e incidindo na construção de políticas e na pauta de muitos movimentos sociais.

Acoplada diretamenteà noção de desenvolvimento rural que gradativamente vinha se consolidando, aparecia também toda a construção político-acadêmica que culminou na conceituação de agricultor familiar, uma ideia-força que reposicionou o debate contemporâneo sobre o rural, contra-argumentando tanto a tese que propagava o fim do campesinato, pela via da inclusão ao modelo capitalista, quanto a tese que apostava na agricultura camponesa como um modelo em si. Cria-se uma espécie de caminho do meio, através de um conceito que se propõe como apaziguador e conciliador. Sem descartar o papel do camponês, reposiciona o debate a partir de uma nova perspectiva teórica que, segundo Fernandes (2010), teria ganhado força no Brasil a partir da publicação do livro derivado da tese de doutorado de Ricardo Abramovay (1992), Paradigmas do Capitalismo Agrário em Questão. 
A partir de uma ruptura com o paradigma marxista, referência fundamental nas discussões acerca da questão agrária, Abramovay apresenta uma nova leitura do mundo rural, inspirada basicamente na situação contemporânea dos países de capitalismo avançado, onde os agricultores de base familiar conseguiram desempenhar um papel importante, integrando-se ao mercado e se perpetuando como um segmento social importante no rural. Desse modo, o autor propõe uma abordagem teórica que diferencia o camponês do agricultor familiar, promovendo, a partir desta distinção, a criação dessa "nova categoria". Nas palavras de Abramovay é possível perceber os principais elementos que definem a ideia de agricultor familiar:

[...] integram-se plenamente a estas estruturas nacionais de mercado, transformam não só sua base técnica, mas sobretudo o círculo social em que se reproduzem e metamorfoseiam-se numa nova categoria social: de camponeses tornam-se agricultores profissionais. Aquilo que era antes de tudo um modo de vida converte-se numa profissão, numa forma de trabalho. [...] Os laços comunitários perdem seu atributo de condição básica para a reprodução material. [...] O ambiente no qual se desenvolve a agricultura familiar contemporânea é exatamente aquele que vai asfixiar o camponês, obrigá-lo a se despojar de suas características constitutivas, minar as bases objetivas e simbólicas de sua reprodução social (ABRAMOVAY, 1992, p. 126-127, 131 apud FERNANDES, 2010).

É importante ressaltar o peso que a construção da ideia de agricultura familiar conquista no contexto político mais recente, espraiando-se, em pouco mais que vinte anos, como vocábulo padrão e como modelo paradigmático de concepção do rural contemporâneo, tanto no meio acadêmico como nas formulações dos diversos atores sociais e do próprio Estado, culminando nas chamadas políticas públicas diferenciadas para o rural, nas quais a categoria "agricultura familiar" é onipresente.

Embora este debate seja bastante relevante, e certamente mereceria ser contemplado em maiores detalhes, creio ser importante frisar pelo menos um ponto específico que dialoga diretamente com a construção da ideia de território nas políticas públicas de desenvolvimento rural. Refiro-me a um dos principais resultados da pesquisa desenvolvida no âmbito do Projeto CUT/ CONTAG, iniciativa que também teve um papel importante na construção da ideia de agricultura familiar, não só no âmbito do Estado, mas também junto aos movimentos sociais, em especial o movimento sindical, principalmente com relação ao eixo da pesquisa coordenado por José Eli da Veiga. Esta pesquisa apontou como proposta, a seguinte hipótese: 


\begin{abstract}
As melhores configurações territoriais encontradas eram aquelas que combinavam agricultura de base familiar forte com um entorno socioeconômico diversificado, dotado de infraestrutura; um desenho que permitia aos espaços urbanos e rurais, de um lado, abrigar o trabalho excedente que deixa a atividade agrícola e, de outro, absorver nas unidades familiares o trabalho descartado nas cidades em decorrência do avanço tecnológico e do correspondente desemprego característico dos anos 1990 (FAVARETO, 2010, p. 28, grifo nosso).
\end{abstract}

Para além da reiteração e naturalização da ideia de agricultura familiar, tem-se, nesta formulação, o delineamento de um projeto que deveria tomar como base para intervenção os "territórios", que, ao conectar adequadamente o urbano e o rural, gerariam impactos positivos e sinergias socioeconômicas, ou seja, um receituário bastante semelhante ao que vimos no contexto do Programa LEADER, e mesmo no que Bagnasco (1977) verificou no caso italiano. Também aparece com peso na proposta a ideia de progressiva desvinculação do rural do agrícola, ideia que ficou ainda mais acentuada a partir dos resultados das pesquisas realizadas no âmbito do Projeto Rurbano, coordenado por José Graziano da Silva, e que também ganhou expressividade na caracterização do rural brasileiro contemporâneo, influenciando posteriormente a concepção de território nas políticas públicas para o rural.

Porém, a veiculação dos resultados dessas duas pesquisas, bem como a própria universalização da categoria agricultura familiar, não passaram sem receber críticas e gerar certa polêmica. Trabalhos como os de Alentejano (2000), Bastos (2006) e Fernandes (2010) alertaram para o fato de que "agricultura familiar" teria sido uma categoria impulsionada por uma orientação teórica específica, com forte influência sobre as políticas públicas, e que, na janela de oportunidade aberta pela situação particular do meio rural no Brasil durante os anos 1990, foi incorporada (por indução ou não) como uma categoria política ou até mesmo identitária por parte significativa dos grupos e movimentos camponeses no Brasil (MEDEIROS, 2001).

Frente a esse processo rápido e envolvente, algumas críticas específicas procuraram problematizar e questionar a ideia de agricultura familiar, mostrando que ela estaria também relacionada a outros processos, como, por exemplo, o novo padrão de política econômica neoliberal adotado no Brasil nos anos 1990 (ALENTEJANO, 2000) e as pressões de organismos internacionais como o Banco Mundial e a FAO (MONTENEGRO, 2006; BASTOS, 2006; VILELA, 1997). Maria Nazareth Wanderley $(2000 ; 2004)$ também se propôs a resgatar este debate, no sentido de problematizar não só a origem da categoria agricultura familiar, como também o suposto "problema teórico" que, para alguns autores, 
a mesma acarretaria. De qualquer maneira, Wanderley, assim como os outros autores citados, também assume o fato de que a ideia de agricultura familiar teria uma relação intrínseca com o Estado e com as políticas públicas, em especial o Programa Nacional de Fortalecimento da Agricultura Familiar (Pronaf), embora ressalte que observar o agricultor familiar meramente como um produto da ação do Estado é reduzir e negligenciar a sua capacidade de assimilação, apropriação e manutenção da história e das tradições camponesas que também lhe são particulares. Ou seja, para autora, por um lado, sim, o agricultor familiar é uma produção ou uma construção social que parte do Estado e, por outro, não seria possível defini-lo tomando como base apenas isso.

O fato a ser destacado aqui é a instauração de um campo de disputa político-acadêmico, que tem como resultado a formulação (ou adaptação) da ideia de agricultura familiar, não apenas em seus contornos teóricos, mas, principalmente, no forte papel que a mesma passou a ter no que se refere à definição das políticas públicas para o rural, e no discurso e na prática de vários movimentos sociais ligados ao rural.

Outra entrada analítica que creio ser interessante para a compreensão do espraiamento desse discurso que se sustenta nos conceitos de agricultura familiar, desenvolvimento rural e, por último, de desenvolvimento territorial é a observação da trajetória de alguns indivíduos que desempenharam um papel determinante nesse processo. Em um texto curto em que busca problematizar sobre a manutenção e a validade das políticas públicas para agricultura familiar no contexto contemporâneo, Cazella (2012) lembra o peso significativamente importante da sociologia rural francesa na formação de um grupo seleto de intelectuais brasileiros, que posteriormente vieram assumir uma posição de destaque e influência no que diz respeito aos projetos políticos para o mundo rural no Brasil, não só na academia, mas também, e principalmente, no intercâmbio desta com as políticas públicas. Como exemplos principais, cita ainda Maria Isaura Pereira de Queiroz, nos anos 1970, e, mais recentemente, Maria Nazareth Wanderley, José Eli da Veiga e Ricardo Abramovay, sendo que esses dois últimos tiveram inserção importante nos ambientes de concepção e elaboração das políticas públicas diferenciadas para o rural, e que, não por acaso receberam a denominação de políticas públicas para a agricultura familiar.

De outro modo, não foi à toa que os resultados dos trabalhos desse grupo de pesquisadores ganharam espaço no âmbito do balizamento conceitual das políticas públicas para o rural. O trânsito de Ricardo Abramovay e José Eli da Veiga no âmbito governamental durante os anos da gestão de Fernando Henrique Cardoso foi decisivo para essa empreitada, sendo que o segundo chegou a presidir 
o Conselho Nacional de Desenvolvimento Rural Sustentável, e suas ideias tiveram reflexo significativo nas diretrizes das políticas para o desenvolvimento rural.

Paralelamente a todas essas discussões, é importante lembrar que o debate sobre a abordagem territorial está também inserido em um contexto de revisão e aprimoramento das políticas de descentralização, iniciados com a Constituição Federal de 1988, que dispõem sobre o processo de municipalização de diversas políticas públicas. Assim, o desgaste e a ineficiência da ação pública no âmbito municipal, durante a década de 1990, são também outras justificativas para o surgimento do discurso da abordagem territorial no âmbito da gestão das políticas públicas. Nesse sentido, a regulação com base no território aparece como uma possibilidade de ação do Estado através da indução das sinergias intersetoriais em contextos intermunicipais, envolvendo diversos segmentos da sociedade que supostamente se articulariam para estabelecer os rumos do desenvolvimento em determinada localidade.

Neste mesmo período, entre o final da década de 1980 e a década de 1990, para além do processo de descentralização federativa, outros fatos importantes devem ser considerados, uma vez que compõem o cenário de mudanças políticas e institucionais que ocorreram no Brasil, e que também influenciaram o escopo das políticas públicas para o mundo rural. Araujo et al. (2010), lembram que no bojo do processo de redemocratização do país, especialmente no pós-1988, algumas mudanças foram desencadeadas. Este ambiente de agitação política, atrelado à intensificação do movimento de luta pela terra, em meados dos anos 1990, e o consequente fortalecimento de grupos sociais ligados à questão rural, impulsionaram um processo de respostas apaziguadoras por parte do governo brasileiro, no sentido de, por um lado, conter o ímpeto e expansão dos conflitos fundiários, e, por outro, atender às demandas desses novos atores que ganhavam espaço no cenário político da redemocratização.

Durante o governo de Fernando Henrique Cardoso, mais precisamente no ano de 1996, foi criado o Programa Nacional de Fortalecimento da Agricultura Familiar (Pronaf). É justamente essa política pública que cria oficialmente e dá visibilidade à categoria "agricultura familiar", a qual, a partir de então, passa a ser objeto de políticas públicas diferenciadas. Isso se dá, também, em consequência das pressões e demandas do movimento sindical dos trabalhadores rurais ligados à Confederação Nacional dos Trabalhadores da Agricultura (Contag) e ao Departamento Nacional de Trabalhadores Rurais da Central Única dos Trabalhadores (DNRT/CUT), que, segundo Lauro Mattei (2010), neste período ampliaram "suas reivindicações por meio das 'Jornadas Nacionais de Lutas' e dos 'Gritos da Terra Brasil', momentos em que ganhou relevância a luta por 
uma política agrícola específica" (MATTEI, 2010, p. 57), a qual acabou sendo traduzida nos termos das políticas para a agricultura familiar.

Ainda segundo Mattei (2010), por outro lado, a elaboração do Pronaf guarda relações próximas também com a elaboração do chamado Relatório FAO/Incra, resultado de uma pesquisa realizada em parceria entre essas duas instituições, com o objetivo de delimitar e definir com maior precisão conceitual a noção de agricultura familiar no Brasil, bem como delinear indicativos e diretrizes para políticas públicas que tivessem como objetivo atender às demandas e fortalecer esse "novo segmento" da população rural. Três anos após a elaboração do Pronaf, em 1999, em continuidade ao processo de reconhecimento (ou construção) das especificidades da agricultura familiar, foi instituído o Ministério de Política Agrícola e Desenvolvimento Agrário (que em 2000 se tornara apenas Ministério do Desenvolvimento Agrário), responsável por concentrar e organizar as questões atinentes à reforma agrária e à agricultura familiar.

Neste mesmo ano, o governo FHC lança também o programa que ficou conhecido como "Novo Mundo Rural”, cujo nome oficial é "Agricultura Familiar, Reforma Agrária e Desenvolvimento Local para um Novo Mundo Rural. Política de Desenvolvimento Rural com Base na Expansão da Agricultura Familiar e sua Inserção no Mercado”. Esse programa, que, na verdade, era a conjugação de outros programas já existentes, principalmente o Pronaf e o Banco da Terra, como o próprio nome indica, tem uma forte conotação de inserção do camponês aos mercados e está fundamentalmente ancorado na perspectiva teórico-conceitual que propõe Abramovay (1992), dentre outros autores. Um dos principais objetivos deste programa é expresso da seguinte forma: "Proporcionar as condições necessárias para que os agricultores familiares desenvolvam atividades produtivas em níveis de competitividade, dentro da realidade e das perspectivas do negócio rural num mundo globalizado" (MDA, 1999, p. 7).

Além disso, como demonstram Montenegro (2006) e Bastos (2006), não são poucas as evidências que atrelam essas novas políticas para a agricultura familiar à agenda neoliberal que vinha sendo implantada durante os anos 1990 no governo FHC. Montenegro (2006), ao trazer para o debate um documento do Banco Mundial, cujo título é "Brazil: the management of agriculture, rural development and natural resources" (RELATÓRIO 11783-BR), expõe e debate o quanto a elaboração dessas novas políticas públicas e a própria ideia de agricultura familiar guardavam relações com preceitos normativos que tinham como proposta a reformulação das estratégias de intervenção do Estado a partir do receituário neoliberal, da neutralização dos conflitos e da dimensão política dos atores no campo, através de um projeto cujo principal objetivo era a 
inserção dos agricultores no mercado. O trecho abaixo, retirado do texto oficial do Relatório 11783-BR, exemplifica essa questão:

O Banco Mundial vê uma agricultura emergindo no futuro como dirigida pela empresa privada, que oferece oportunidades para novos concorrentes e está regulada por um conjunto mínimo e neutro de intervenções governamentais (BANCO MUNDIAL, 1994, p. 41 apud MONTENEGRO, 2006).

Mais do que isso, a agenda neoliberal, em conjunto com a matriz teórica que emergia na mesma época, e que repaginava as discussões sobre o rural, também acarretaram em uma secundarização das discussões e das políticas de reforma agrária, não que anteriormente existisse um esforço substantivo ou uma agenda de políticas que realmente estivessem concretizando a reforma agrária, em termos de políticas públicas efetivas. Pelo contrário, por mais que a questão agrária anteriormente fosse preponderante ou, pelo menos mais expressiva no bojo das discussões acadêmicas sobre o rural, esse debate não possuía penetração e influência no âmbito das políticas públicas ou a possuía apenas retórica e discursivamente. Exemplo disso é o fracasso das articulações políticas e da implementação do Plano Nacional de Reforma Agrária (ou I PNRA), ainda durante o governo Sarney (1985-1989) (MONTE, 2013).

Neste sentido, as formulações em torno da ideia de desenvolvimento rural, em especial as políticas públicas para a agricultura familiar, parecem ter cumprido uma função de esfriar os ânimos da luta pela terra (dado o contexto específico em que se inscreviam, marcado pela proliferação de conflitos no campo no governo $\mathrm{FHC}^{2}$ ), ao mesmo tempo em que paulatinamente "congelavam" a agenda da reforma agrária, substituindo-a pela agenda do desenvolvimento rural, da agricultura familiar e, mais recentemente, do desenvolvimento territorial rural, sem necessariamente abandonar a questão agrária, mas conferindo-lhe um status secundário no escopo das políticas públicas.

Por outro lado, é igualmente importante pensar que as políticas para o desenvolvimento territorial não são o único componente desse processo mais complexo de desmonte ou de desconsideração da reforma agrária, no escopo da agenda dos últimos governos. Há também outras dinâmicas que contribuem para esse processo, e que possuem maior fôlego e força política, como, por exemplo, as ações ligadas ao fomento do agronegócio, e toda a estratégia de criminalização da luta pela terra, que envolve inclusive a mídia. De todo modo, o que pretendo

Os dois exemplos mais emblemáticos que ocorreram neste período foram os casos dos conflitos fundiários em Corumbiara (RO) em 1995, e Eldorado dos Carajás (PA) em 1996, quando dezenas de trabalhadores sem-terra acampados foram assassinados. 
suscitar com esta problematização é que, a meu ver, as políticas para a agricultura familiar e, por extensão, as políticas de desenvolvimento territorial, cumprem uma função (intencional ou não), pelo menos no plano semântico e retórico, de repaginar as discussões e as estratégias de intervenção sobre o rural. Como bem afirmam Miná e Medeiros (2011, p.18), “indícios de uma releitura do rural encontram-se na incorporação da abordagem territorial". Mas, para além da reorientação assinalada por esses autores, que diz respeito à superação do enfoque setorial, à consideração das sinergias entre o urbano e o rural, e de todas as outras contribuições trazidas pelo enfoque territorial do rural, no meu entender, é preciso também levar em conta um efeito nem sempre lembrado acerca do contexto político em que essa proposta emerge, e que é caracterizado pelo obscurecimento dos conflitos e da dimensão agrária e fundiária no âmbito das políticas públicas para o rural.

É, pois, de modo semelhante ao que se deu na Europa, mas não exatamente da mesma forma, que a abordagem territorial passa a ser assumida como uma categoria de orientação das políticas públicas no Brasil. Ou seja, a partir de alguns desdobramentos específicos sobre a ideia de agricultura familiar, adicionada pelos debates contemporâneos acerca das novas ruralidades, da sustentabilidade, da descentralização e da necessidade de superação da intervenção em escala municipal, que se consolida o terreno propício para a emergência do discurso que sustenta as políticas de desenvolvimento territorial no início dos anos 2000, mais precisamente em 2003, no primeiro ano do governo Lula.

\section{PECULIARIDADES NO CASO BRASILEIRO: REFORMAAGRÁRIA, POLÍTICA TERRITORIAL E POLÍTICA SOCIAL NO PROJETO PETISTA}

Há que se ressaltar, assim como lembram Araújo et al. (2010) e Delgado e Leite (2013), que a ascensão do Partido dos Trabalhadores (PT) ao governo federal foi também um elemento central para a consolidação do projeto político para a agricultura familiar (incluindo aqui as políticas territoriais) que vinha sendo gestado e demandado, em grande medida, pelos sindicatos e movimentos sociais do campo, os quais, a partir de 2003, passam também a integrar e a "construir por dentro do Estado" (MÜLLER, 2007), influenciando o desenho e a implementação de uma série de políticas públicas diferenciadas. De todo modo, é válido lembrar que, anteriormente à posse de Lula em 2003, o tema da reforma agrária ainda figurava como parte constitutiva da agenda política do PT, embora a política de 
reforma agrária tenha perdido muito fôlego nos governos petistas, até mesmo quando comparada ao período do governo FHC.

Curiosamente, mesmo com a relativa permeabilidade do governo Lula a alguns movimentos sociais, principalmente na ocupação de alguns quadros políticos no MDA, a agenda da reforma agrária não avançou no âmbito das políticas públicas. O interessante deste fato é que, se no governo FHC a agenda da agricultura familiar já vinha sendo implementada como reflexo de um processo de incorporação das diretrizes neoliberais para as políticas de intervenção sobre o rural, com a ascensão do governo petista ao poder em 2003, os movimentos sociais (pelo menos aqueles que passaram a compor e integrar o governo, em especial o movimento sindical) parecem mais reforçar esse mesmo processo de consolidação da agricultura familiar como uma categoria de política pública, do que buscar fortalecer e implementar a agenda da reforma agrária, que tanto na época das eleições de 2002 quanto nos anos iniciais do primeiro mandato ${ }^{3}$, ainda compunha a plataforma política de Lula. Assim, parece que houve um processo de incorporação do discurso da agricultura familiar também por parte considerável dos movimentos sociais e grupos da sociedade civil, que passaram a "jogar o jogo" a partir das regras postas, das possibilidades ofertadas e dos limites estabelecidos por este paradigma específico que, desde o início dos anos 1990, espraiou-se na forma de pensar e elaborar as políticas públicas para o rural.

Então, nesse contexto político-institucional foi criada a Secretaria de Desenvolvimento Territorial, no âmbito do Ministério do Desenvolvimento Agrário (SDT/MDA), à qual caberia a responsabilidade de desenhar e implementar a política de desenvolvimento territorial rural, primeiro com a realização do Programa Nacional de Desenvolvimento Sustentável dos Territórios Rurais (Pronat), em 2003, e depois com o Programa Territórios da Cidadania (PTC), em 2008.

Para além do contexto político e do conjunto de atores que se engajaram na constituição de ambos os processos, podemos citar dois encadeamentos que evidenciam os vínculos entre a ideia de agricultura familiar e a abordagem do desenvolvimento territorial. Primeiro, é preciso lembrar que o Pronat é derivado de uma linha específica do Pronaf (Infraestrutura e Serviços), antes com incidência municipal, e que, após a formulação do Pronat, passa a ter a base territorial (um recorte intermunicipal) como referência. Segundo, há o fato de que a delimitação ou a escolha dos territórios que passaram a fazer parte do escopo

3 Embora tenha havido um esforço para a construção do II Plano Nacional de Reforma Agrária, por um grupo de especialistas coordenado por Plínio de Arruda Sampaio, a versão final do Plano e a sua implementação não atenderam o compromisso estabelecido durante as eleições com os movimentos sociais ligados à luta pela reforma agrária. 
do Pronat, em 2003, tinha como um dos principais critérios a concentração de agricultores familiares.

Para Araújo et al. (2010), no caso brasileiro, a emergência da abordagem territorial apresenta, ainda, outras questões particulares que complementam aquelas acima mencionadas. Diferente do que ocorreu na Europa, no caso do Programa LEADER, por exemplo, a política territorial no Brasil, embora traga, evidentemente, a valorização da intervenção em escala subnacional, foi estruturada de modo a preservar a coordenação no âmbito federal, garantindo a elaboração de diretrizes em escala nacional, bem como a articulação com outras instâncias e políticas nacionais. Essa dimensão de coordenação nacional, a cargo da SDT e, no caso do Programa Territórios da Cidadania (PTC), sob responsabilidade da Casa Civil, permite também a inserção e o diálogo da política territorial com as diretrizes e prioridades do governo, como é o caso da recente ênfase dada às ações de combate à pobreza, principalmente no âmbito do PTC, a partir de 2008.

O Programa Territórios da Cidadania (PTC) pode ser interpretado como uma segunda geração, bem mais audaciosa, de políticas concebidas a partir da abordagem do desenvolvimento territorial. Enquanto o Pronat teve o papel de iniciar e, em grande medida, experimentar a gestão de políticas públicas para o rural em escala territorial, criando os territórios, propondo novas formas de conceber o rural e estruturando espaços diferenciados de controle, articulação e participação social, o PTC surge com a intenção de articular e conectar uma gama variada de políticas que incidem em um mesmo território, buscando ampliar e dar fôlego à proposta inicial da intersetorialidade. De modo complementar, mas não menos importante, articulado às principais diretrizes do governo Lula (combate a fome e erradicação da pobreza), o PTC passou a costurar mais claramente as ideias iniciais da abordagem territorial às políticas sociais relacionadas ao enfrentamento da pobreza rural.

Como bem enfatizam Delgado e Leite (2011), o PTC, ao mesmo tempo em que dá sequência à abordagem territorial, está também ancorado nos contornos da chamada Agenda Social do Governo Federal, tendo como objetivo a

[...] superação da pobreza e geração de trabalho e renda no meio rural por meio de uma estratégia de desenvolvimento territorial sustentável" e tratava-se da "principal estratégia do governo para redução das desigualdades no meio rural, por meio de integração de políticas públicas (DELGADO; LEITE, 2011, p. 94).

Essa parece ser uma questão particular, no que diz respeito à apropriação da ideia de desenvolvimento territorial no contexto brasileiro. Embora seja preciso 
ainda descrever com maior atenção e detalhamento o processo originário de onde emanam as ideias que sustentam a proposta de desesenvolvimento territorial, não há muitas dúvidas de que as mesmas advêm da influência de organismos internacionais e da produção acadêmica (em grande medida associada a esses mesmos organismos internacionais) de um grupo específico de pesquisadores. Porém, o que me parece necessário compreender são as peculiaridades em que esse processo de apropriação ocorre. A releitura da ideia de território, na ótica do combate à pobreza adotada pelo governo Lula, em especial no enfoque proposto pelo PTC, é um indicativo de que a agenda da política social estaria se sobressaindo frente aos preceitos anteriores que orientavam a ideia de desenvolvimento territorial e de agricultura familiar. A presença cada vez mais forte do Ministério de Desenvolvimento Social e Combate à Fome (MDS) sobre as políticas da agricultura familiar é outro elemento que aponta para essa hipótese, e obviamente necessita ser investigada com mais profundidade.

Outros elementos que contribuem para refletir sobre essa questão dizem respeito às diferentes fases em que o projeto político do governo Lula pode ser observado. Como aponta Fagnani (2011), no primeiro mandato petista a implementação das políticas sociais esteve comprometida com a ideia de "transição necessária”. O autor classifica este primeiro período, que vai de 2003 a 2005, como uma fase em que impera a ambiguidade entre mudança e continuidade, que é marcada pela manutenção da ortodoxia econômica do período anterior, em especial em termos de política econômica. Já no segundo mandato, a partir de 2006, denominado por Fagnani (2011) como "ensaios desenvolvimentistas", inicia-se um processo de alterações significativas na cúpula da área econômica, principalmente no âmbito do Ministério da Fazenda, o que implica uma proposta em que o crescimento econômico volta a ganhar destaque e centralidade. Segundo o autor, a partir dessas mudanças, "passou a haver uma articulação mais convergente entre os objetivos macroeconômicos e sociais [...], abrindo mais espaço para os gastos sociais" (FAGNANI, 2011, p. 5).

É, então, nesse contexto, a partir de 2007, que as políticas sociais conseguem ganhar respaldo e passam ter possibilidades realmente concretas de um aumento de escala, tal como era o objetivo do governo petista eleito em 2003. Mas o que verdadeiramente garantiu o respaldo para o conjunto de políticas sociais do governo Lula foi a aliança (traduzida no chamado "pacto social amplo") capaz de unir na mesma plataforma política o crescimento econômico e as políticas sociais. Para Erber (2011), em torno dessas duas ideias-força seria construída uma nova "convenção de desenvolvimento". Assim, o projeto político que ganha corpo a partir da reeleição de Lula em 2006, que vem sendo frequentemente chamado 
de neodesenvolvimentista, parece assumir a sua forma atual no Programa de Aceleração do Crescimento (PAC) e na redução da pobreza, que tem como política de referência o Programa Bolsa Família (PBF).

Erber (2011) afirma ainda que um pressuposto central que sustentaria essa aliança entre crescimento econômico e política social seria o fato de que o modelo de inclusão promovido por esta última, apesar dos avanços materiais e concretos nas condições de vida dos mais pobres, não comprometeria os interesses dos grupos de maior renda. Para o autor, o modelo de política social estaria também relacionado a um esquema em que a "redução dos conflitos, inerente à política e sua forma de implementação, e, inclusive pelo baixo custo fiscal que envolve, é de interesse também dos grupos de maior renda, estabelecendo uma ponte entre as duas convenções” (ERBER, 2011, p. 38).

Ainda com referência ao pacto social ampliado, que sustenta politicamente a coalizão do governo Lula, e que, de maneira geral, se estende para o governo Dilma, é preciso relembrar um ponto significativo que nos remete ao debate sobre o rural. Refiro-me ao papel crucial desempenhado pelo setor do agronegócio, o qual via uma estratégia agroexportadora de commodities, atuando como um dos principais atores na manutenção do saldo positivo da balança comercial e um dos pilares para o modelo macroeconômico definido pelo governo. $\mathrm{O}$ fato é que nesse pacto político que carrega os interesses do agronegócio, é impensável um processo de democratização do acesso a terra, visto que isso iria de encontro à estratégia de reprodução do próprio agronegócio.

Penso que através de uma leitura que considere as implicações desse contexto político e das inflexões assumidas pelo projeto petista a partir de 20062007, seria interessante proceder a uma interpretação diferenciada das políticas de desenvolvimento territorial. O Programa Territórios da Cidadania (PTC), desenhado e implementado dentro deste ambiente político e conduzido sob a tutela do MDS é um fato importante, e indica que as políticas públicas de desenvolvimento territorial estariam sendo circunscritas à lógica da política social e à sua função dentro do projeto político que vem se construindo desde 2006.

Neste sentido, mais do que um olhar sobre as adaptações institucionais, as reorientações da rota e as já visíveis inclinações para um enfoque de combate à pobreza e de política social, as políticas de desenvolvimento territorial e a própria ideia de território também podem ser interpretadas a partir da mesma crítica que se faz às políticas sociais de caráter compensatório, que velam ou arrefecem os conflitos sociais, que permanecem ou até mesmo se intensificam no esquema montado pelo projeto político (ou pela convenção) de desenvolvimento estabelecido. Ao mesmo tempo em que as políticas sociais (e talvez já considerando 
aqui a políticas de desenvolvimento territorial) visam o aumento da renda (e não a redistribuição da riqueza) e inserem as camadas mais pobres no mundo do consumo, por outro lado, na outra dimensão do projeto político, aquelas ligadas ao crescimento econômico e aos intensos processos de apropriação de terras e dos recursos naturais relacionados aos grandes projetos de investimento que aliam capital público e privado, são implementadas e reconfiguram drasticamente o tecido social de inúmeros territórios pelo país, exercendo enorme pressão sob a realidade e os modos de vida dos camponeses.

Ou seja, de um lado, as políticas territoriais com papel de política social têm pouca influência sobre as grandes dinâmicas políticas e econômicas do contexto (do território?) em que se inserem (mesmo no que tange à agricultura, haja vista o intenso processo de avanço do agronegócio, em uma retomada/ continuação do processo de incorporação dos pequenos agricultores); e, de outro lado, os grandes projetos de investimento e infraestrutura que avançam sobre os contextos rurais e vão remodelando a paisagem, reorganizando as relações sociais e estabelecendo dinâmicas de territorialização vinculadas aos interesses de corporações da iniciativa privada que ancoram a sua atuação no escopo de grandes obras financiadas pelo PAC e na manutenção da panaceia do crescimento com inclusão. Essa é uma ideia que precisa ser retomada e melhor discutida futuramente (fazendo uso de mais evidências empíricas ${ }^{4}$ ), mas que tentei detalhar, de forma preliminar, ao longo deste trabalho.

\section{CONSIDERAÇÕES FINAIS}

Conforme busquei evidenciar neste trabalho, embora as políticas de desenvolvimento territorial, na sua concepção inicial, tenham sido desenhadas a partir de questões e debates temáticos específicos aqui identificados, de lá para cá, isso não se manteve intacto ou inalterado, visto que foram sendo incorporadas outras discussões à abordagem territorial, bem como outros significados foram sendo produzidos no processo de implementação dessas políticas. Obviamente, ainda é necessário um maior detalhamento da pesquisa na recomposição deste processo originário do discurso sobre o desenvolvimento territorial no caso brasileiro, assim como também é preliminar o mapeamento dos "novos" temas que passam a incorporar e encorpar a ideia de território nas políticas públicas de

\footnotetext{
4 Em minha tese em andamento, promovo essas discussões e debates a partir de dois estudos de caso realizados nos estados de São Paulo e da Bahia.
} 
desenvolvimento rural5. Todavia, o que busquei identificar foram sinalizações desse processo difuso e complexo em que se dá a construção e a organização das narrativas e dos discursos sobre a abordagem territorial.

Para além da mera listagem dos temas e das propostas que vão sendo acopladas gradativamente ao escopo da política pública, este trabalho buscou identificar as conexões e implicações que decorrem deste processo específico, bem como a produção de significados e os efeitos que daí emanam em termos de ordenamento das relações entre os atores envolvidos em um contexto político mais amplo. A contínua construção semântica, através da qual uma política pública se estabelece, implica em diversas apropriações e incidências de interesses, uns mais explícitos, outros menos. O traslado da abordagem territorial, que parte da incorporação de um receituário europeu (francês, em especial) para uma nova forma de intervenção e governo ${ }^{6}$ sobre o rural, especificamente a partir da construção da ideia de agricultura familiar, que também é objeto de propagação das diretrizes de diversos organismos internacionais, encontra no contexto brasileiro uma realidade particular, que, ao mesmo tempo em que absorve, também remodela esse "pacote" a partir de suas peculiaridades políticas e sociais.

Entretanto, uma questão específica me chama a atenção, e gostaria de reforçá-la como um tema em potencial para discussões futuras. Trata-se do fato de que a política pública de desenvolvimento territorial parece não dialogar com uma série de outros processos sociais em voga, que tem a luta pela terra e pelo território como elementos centrais da ação política. Povos indígenas, quilombolas, assentados, ribeirinhos e uma diversidade de populações que vêm sendo chamadas genericamente de "povos e comunidades tradicionais", mais recentemente, passam a encampar diversos processos de disputa pelo direito à demarcação de seus territórios, trazendo à tona a questão fundiária e os inúmeros conflitos existentes nesses territórios. Se, por um lado, as políticas públicas de desenvolvimento territorial criam "Territórios sem Terra", ou seja, sem que a dimensão fundiária e os inúmeros conflitos por terra e território

5 Ressalto que considero esse processo sempre como inacabado. Ou seja, apesar de haver períodos de maior estabilidade, não há um momento em que podemos dizer que a política pública "congela" ou se estabiliza definitivamente. Sempre haverá novas orientações políticas, novos interesses, que terão como objetivo reorientar o caminho e o significado de uma política pública. E isso ocorre não só em escala macro, no âmbito nacional, como também (e principalmente) no processo de ressignificação e apropriação semântico-cognitiva e operacional que os atores desencadeiam na ponta, através do processo de implementação. Uma referência que contribui para reflexões sobre políticas públicas é o estudo de Lejano (2006).

6 Trato aqui "governo" na ascepção foucaultiana do termo. No que tange ao debate sobre governamentalidade e políticas públicas, ver Porto (2014).

O título da minha tese em andamento é justamente: "Territórios sem terra: os discursos, os sujeitos e o mundo da política pública de desenvolvimento territorial rural." 
sejam evidenciados, por outro, diversos casos e experiências de afirmação étnico-territorial passam a emergir e ganhar visibilidade no cenário nacional. É justamente a partir dessa questão, desse afastamento entre o "território das políticas públicas" de um lado, e o "território dos conflitos" de outro, que creio na importância de seguir refletindo e problematizando as políticas públicas de desenvolvimento territorial.

\section{REFERÊNCIAS}

ABRAMOVAY, R. Paradigmas do capitalismo agrário em questão. São Paulo: Hucitec; Rio de Janeiro: Anpocs; Campinas: UNICAMP, 1992.

ALENTEJANO, P. R. R. O que há de novo no rural brasileiro? Terra Livre, São Paulo, v. 15, p. 87-112, 2000.

ARAUjO, T. B.; GUIMARÃES NETO, L.; SANTOS, V. M. Pensando o futuro das Políticas de Desenvolvimento Territorial Rural no Brasil. In: ARAUJO, T. B. (Org.). Políticas de Desenvolvimento Territorial Rural no Brasil. Brasília: IICA, 2011. p. 197-216. v. 1.

BAGNASCO, A. Tre Italie. La problematica territoriale dello sviluppo italiano, Bologna: Il Mulino, 1977.

BASTOS, F. Ambiente institucional no financiamento da agricultura familiar. São Paulo: Polis; Campinas: CERES/UNICAMP, 2006.

CAZELLA, A. A. Agricultura familiar: ainda é possível se diferenciar. Carta Maior, São Paulo, p. 1 - 5, 6. nov. 2012.

DAGNINO, E. Sociedade civil, espaços públicos e a construção democrática no Brasil: limites e possibilidades. In: DAGNINO, E. (Org.). Sociedade civil e espaços públicos no Brasil. São Paulo: Paz e Terra, 2002.

DELGADO, N.; LEITE; S. Gestão social e novas institucionalidades no âmbito da política de desenvolvimento territorial. In: DELGADO, N.; LEITE, S. (Org.). Políticas públicas, atores sociais e desenvolvimento territorial no Brasil. Brasília: IICA, 2011. (Série Desenvolvimento Rural Sustentável, 14).

Atualização das políticas de desenvolvimento territorial no meio rural brasileiro. In: LEITE, S. P. (Org.). Políticas de desenvolvimento territorial e enfrentamento da pobreza rural no Brasil. 1. ed. Brasília: IICA, 2013. p. $125-148$. v. 1. 
DELGADO, N.; GRISA, C. Institucionalidades, governança e projetos territoriais na política de desenvolvimento rural no Brasil. In: LEITE, S. P. (Org.). Políticas de desenvolvimento territorial e enfrentamento da pobreza rural no Brasil. 1. ed. Brasília: IICA, 2013. p. 239-287. v. 1.

ERBER, F. As convenções de desenvolvimento no Governo Lula. Revista de Economia Política, v. 31, n. 1, 2011.

FAGNANI, E. A política social do Governo Lula (2003-2010): perspectiva histórica. Campinas: IE/UNICAMP, 2011

FAVARETO, A. Tendências contemporâneas dos estudos e políticas de desenvolvimento territorial. In: BACELAR, T. (Org.). Políticas de desenvolvimento territorial rural no Brasil - avanços e desafios. Brasília: IICA, 2010.

FERNANDES, B. M. Questão agrária: conflitualidade e desenvolvimento territorial. In: SPOSITO, E. S.; SANT'ANNA NETO, J. L (Org.). Uma Geografia em movimento. São Paulo: Expressão Popular, 2010. p. 505-560. v. 1.

LEJANO, R. Frameworks for policy analysis: merging text and context. Nova York: Routledge, 2006. 269p.

MATTEI, L. Análise da produção acadêmica do Programa Nacional de Fortalecimento da Agricultura Familiar (PRONAF) entre 1996 e 2006. Estudos Sociedade e Agricultura, v. 18, p. 56-97, 2010.

MEDEIROS, L. S. de. Sem terra, assentados, agricultores familiares: considerações sobre os conflitos sociais e as formas de organização dos trabalhadores rurais brasileiros. In: GIARRACA, N. (Org.). Una nueva ruralidad en America Latina? 1. ed. Buenos Aires: Clacso, 2001. p. 1-382.

MINA, M.; MEDEIROS, L. Marco jurídico-normativo para o desenvolvimento rural com enfoque territorial. In: DELGADO, N.; LEITE, S. (Org.). Políticas públicas, atores sociais e desenvolvimento territorial no Brasil. Brasília: IICA, 2011. (Série Desenvolvimento Rural Sustentável, 14).

MINISTÉRIO DO DESENVOLVIMENTO AGRÁRIO. Marco Referencial para o apoio ao Desenvolvimento de Territórios Rurais. Brasília: MDA, 2005. (Documentos Institucionais, 2).

MINISTÉRIO DO DESENVOLVIMENTO AGRÁRIO. O Novo Mundo

Rural - projeto de reformulação da reforma agrária em discussão pelo governo. Brasília: MDA, 1999. 
MONTE, F. C. D. O INCRA e a política de assentamentos rurais: um estudo sobre processos político-administrativos de ação pública. 2013. Tese (Doutorado em Ciências Sociais) - Programa de Pós-Graduação de Ciências Sociais em Desenvolvimento, Sociedade e Agricultura, Universidade Federal Rural do Rio de Janeiro, Rio de Janeiro, 2013.

MONTENEGRO, J. Desenvolvimento em (des)construção: narrativas escalares sobre desenvolvimento territorial rural. 2006. Tese (Doutorado em Geografia) - Programa de Pós-Graduação em Geografia, Universidade Estadual Paulista Júlio de Mesquita, Presidente Prudente, 2006.

MÜlLER, A. L. A construção das políticas públicas para a agricultura familiar no Brasil: o caso do Programa de Aquisição de Alimentos. 2007. Dissertação (Mestrado em Desenvolvimento Rural) - Programa de PósGraduação em Desenvolvimento Rural, Universidade Federal do Rio Grande do Sul, Porto Alegre, 2007.

OFFEN, K. The territorial turn: making black territories in Pacif Colombia. Journal of latin American Geography, v. 2, n. 1, p. 43-73, 2003.

PORTO, J. R. S. Uma analítica do poder para as políticas públicas: Foucault e a contribuição da Anthropology of Public Policy. Estudos Sociedade e Agricultura, Rio de Janeiro, v. 22, n. 2, p. 360-385, 2014.

PROJETO CUT/CONTAG. Desenvolvimento e Sindicalismo Rural no Brasil. Caderno de Apoio aos Seminários Microrregionais. São Paulo: CUT/ CONTAG, 1999.

SCHNEIDER, S.; TARTARUGA, I. P. Território e abordagem territorial: das referências cognitivas aos aportes aplicados à análise dos processos sociais rurais. Raízes, Campina Grande, v. 23, n. 1/2, p. 99-116, 2006.

SHORE, C.; WRIGHT, S. \& PERÒ, D. (Eds.). Policy Worlds. Anthropology and the analysis of contemporary power. New York; Oxford: Berghan Books, 2011.

VILELA, S. L. de O. Qual a política para o campo brasileiro? Do Banco Mundial ao Pronaf: a trajetória de um novo modelo? In: CONGRESSO DA SOBER, 35. 1997, Natal. Anais... Natal, 1997, 18 p.

WANDERLEY,M.N. B. Agricultura familiar e campesinato: rupturas e continuidade. Estudos Sociedade e Agricultura, Rio de Janeiro, v. 21, p. 42-61, 2004. A valorização da agricultura familiar e a reivindicação da ruralidade no

Brasil. Desenvolvimento e Meio Ambiente, Curitiba,v. 2, p. 29-37, 2000. 